\title{
Study on the Influence of Seasonal Diversity Deduction of Landscape Plants on Landscape Vision
}

\author{
Shengju Li ${ }^{1}$, Xue Wang ${ }^{1}$, Yaosheng Zhang ${ }^{1}$, Yuehua Zhang ${ }^{1}$ and Li Lan ${ }^{2 *}$ \\ ${ }^{1}$ Jiamusi University, Jiamusi City, Heilongjiang Province, 154007, China \\ ${ }^{2}$ School of Data Science and Software Engineering, Wuzhou University, Wuzhou City, Guangxi Province, 543000, China
}

\begin{abstract}
Urban garden landscape is a topic of great concern in the process of modern urban construction. It belongs to the landscape with vitality in the construction process. The plant landscape is also the product of the combination of economy, politics, culture and technology. The cold land plants belong to the only life-changing and cyclical elements in the garden design process. They use the seasonal changes of their distinctive features to realize the planning and design, which can effectively enrich the overall landscape effect. The seasonal changes of garden plants in cold regions mainly include space and color. The seasonal changes of color include leaves, flowers, fruits and branches, and the spatial characteristics are different periods of plants. In the process of realizing the garden configuration, it is important to comprehensively study the seasonal changes of plants, which can effectively improve the role of gardens. The study analyzes the influence of seasonal changes of garden plants on the landscape construction of garden space from three aspects: function, season and beauty. Therefore, the characteristics of seasonal changes of garden plants in cold regions are analyzed, so as to improve the rationality of landscape plant configuration in different seasons, and improve the level of garden landscape construction.
\end{abstract}

\section{Introduction}

Garden construction can effectively control the quality of the environment, availably improve people's air quality, beautify people's living environment and improve people's living standards [1]. The quality of garden construction can effectively measure the overall development level of society, and can also improve the quality of gardens, thereby further improve people's quality of life [2]. Planting of plants is also important for environmental protection [3]. In the process of garden space construction, plants are important content. Different plants have different needs in different growing environments. Plants have different changes in different seasons, which have different effects on the creation of garden space [4]. Ecological gardens appeared in the 1920s. Prior to China's, the study of landscape plant landscaping in foreign countries is mainly in the process of actual green space construction. The main pursuit of rich and colourful plant landscapes is to show the importance of the introduction and cultivation of garden plants abroad, especially those with high ornamental value. Chinese gardens are gradually developing in the cultivation of flowers and trees. In the process of continuous social development, the connotation and content of plant landscaping are also constantly developing. At present, relevant researchers in the study of plant landscaping are mainly based on the ecological perspective on the landscape green space pattern [5], function, vegetation structure and ecological benefits. The theory of the relationship between phonology and plant landscape are analyzed.

\section{Experimental plot and sampling method}

\subsection{The cooler of garden plants}

The colour of garden plants mainly manifests in leaves, flowers and fruits. The colour of most of the leaves of plants is realized during the seasonal changes. The degree of change of different hues mainly includes monochromatic leaves and collared leaves. The flowers and fruits of most garden plants gradually sprout, change and fall through the changing seasons. Although there are no significant changes in the colour of the plant parts and organs themselves, there is also a change in color during the changing seasons, which affects the landscape. Collared leaf garden plants refer to plants whose plants have large changes in hue during the changing seasons. The flower and fruit color of the plant are explained. The flowers and fruits of most garden plants are not like leaves, but they change continuously during the seasons, it is germination or apoptosis during the reincarnation of the four seasons, but it still makes the viewing of plants in different seasons not very effective. The effects of different seasons of colour and landscape are different, so that flowers and fruits inject new vitality into the

*Corresponding author's e-mail: 1ljmsu@163.com 
landscape effect during the changing seasons.

\subsection{Garden space}

The definition of physical space in related books is made up of physical entities and through the vertical plane, the ground plane and the top plane or a range of three. Based on different top planes, the landscape space of plants mainly includes covering and vertical space. The vertical space is a plant that uses a tree shape vertically upward and a narrow crown width, and is combined with the ground plane, the top plane is relatively spacious, and also has a vertically upward direction sense. The covering space is a space enclosed by the top of the canopy dense large arbor, which can give people a strong sense of belonging. Based on the vertical planes of different spaces, the space of the plant landscape mainly includes closed, open and semi-open spaces. Open space mainly refers to the fact that people's sight is higher than that of plants, and it is easy to see the outer space, which is non-private and extroverted. There are two main types of semi-open spaces. The first one is that people are partially obscured by plants and can only see the distant space through the pores between plants. The second type is half open and half closed in the garden space. It is a unilateral open space, and people's sights are sometimes hindered and sometimes not hindered. The seasonal variation of garden plants refers to the deciduous plants in the garden. After the early spring, the new branches will germinate and germinate, which will make the plants withered in winter or autumn, and have strong openness.

Most of the garden plants have their own unique and natural form, but there are also many kinds of tree species, such as spherical, spinning cone, spire and cone. Plant branch height or branch level development and upward extension, branch leaf evacuation and concentration degree have different scenes during the seasonal phase change, which gives a particularly strong aesthetic. In the winter, after the leaves of the trees fall, the trunks of some plants have a branching posture, giving people a charm of Chinese painting. The posture of these garden plants can enhance people's interest and attract people's attention. Through the interaction with the surrounding garden elements, a unique artistic conception can be formed. In addition, it can also reflect the surrounding environment to form a unique local landscape.

\subsection{Plant season phase changes and seasons are closely related}

In the cold regions of China, the climate varies from region to region, such as the northeast and the south. The four seasons in the north are distinct, and the color and shape of the plants are constantly changing during the seasonal changes. In the south, the temperature difference is small in the whole year, so the seasonal phase change is not obvious, and even some areas can't fully feel the seasonal changes. In the process of seasonal changes in the north, spring is the spring season, the seasons of bright colors of plants, the summer plants have the characteristics of large shades of the crown, the autumn is autumn and high, and the fruit is full of fruit, while the changes of winter plant colors are more monotonous. Therefore, in the process of matching garden plants in the north, based on the changes of the four seasons, a comprehensive and comprehensive arrangement should be realized to avoid the plants being too monotonous throughout the year, resulting in no vitality of the landscape.

(1) Relatively abundant: $\mathrm{RA}=\sum_{i=1}^{s} N_{i}\left(N_{i}-1\right) / N(N-1)$

(2) Relative significan ce: $\mathrm{RD}=\sum_{i=1}^{\mathrm{s}} H / \ln S$

(3) Relative frequency: $\mathrm{RF}=\mathrm{D}_{\mathrm{mg}}=L(S-1) / \ln N$

(4) Important value : (IV) $=\mathrm{RA}+\mathrm{RD}+\mathrm{RF}$

Note: $H^{\prime}$ is the Shannon-wiener index; $\mathrm{E}$ is the Pielou index; $\mathrm{C}$ is the Simpson index; DMG is the Margalef index; $\mathrm{S}$ is the number of species in the sample; $\mathrm{Pi}$ is the ratio of the number of individuals in the ith species in the community, $\mathrm{Pi}=\mathrm{Ni} / \mathrm{N} ; \mathrm{N}$ is the total number of individual samples; $\mathrm{Ni}$ is the number of individuals of the i-th species (in Tab. 1).

Table 1. Statistics of college plots and indigenous woody flora

\begin{tabular}{llll||lll}
\hline \multicolumn{3}{c}{ Woody flora of college plot community } & \multicolumn{3}{c}{ Indigenous community woody flora } \\
\hline Phylum & Family & Genus & Species & Family & Genus & Species \\
\hline Gymnosperm & 2 & 5 & 13 & 4 & 8 & 34 \\
Dicotyledon & 27 & 57 & 103 & 37 & 81 & 357 \\
Monocotyledon & 1 & 0 & 0 & 1 & 1 & 1 \\
The total & 31 & 64 & 116 & 41 & 90 & 392 \\
\hline
\end{tabular}

The hue changes of plants in northern China all year round will have different artistic conception for garden space. Garden landscape is a particularly important medium in this process. In the process of blooming or fading of various flowers and trees, it can fully display the seasonal changes of seasons, which is the main reason that traditional gardens can transform plants into artistic conception. The understanding of the different characteristics of the plant season is, to a certain extent, a cultural deposit, and it is also a comprehensive observation and sublimation of ancient literati for the life of nature (in Tab. 2). 
Table 2. Typical random sample plots reserve Forest community succession alpha diversity

\begin{tabular}{llllllll}
\hline \multirow{2}{*}{ PLOT-1 } & & MEADOW & BIRCH & LARCH & WEED & OAKR & RED-PINE \\
& $\mathrm{H}^{\prime}$ & $1.62 \pm 0.43 \mathrm{~b}$ & $2.44 \pm 0.19 \mathrm{ab}$ & $2.54 \pm 0.24 \mathrm{a}$ & $2.58 \pm 0.20 \mathrm{ab}$ & $2.67 \pm 0.03 \mathrm{a}$ & $2.27 \pm 0.20 \mathrm{ab}$ \\
& $\mathrm{E}$ & $0.62 \pm 0.09 \mathrm{a}$ & $0.75 \pm 0.04 \mathrm{a}$ & $0.74 \pm 0.06 \mathrm{a}$ & $0.75 \pm 0.06 \mathrm{a}$ & $0.81 \pm 0.01 \mathrm{a}$ & $0.68 \pm 0.06 \mathrm{a}$ \\
& $\mathrm{C}$ & $0.32 \pm 0.09 \mathrm{a}$ & $0.14 \pm 0.02 \mathrm{a}$ & $0.14 \pm 0.05 \mathrm{a}$ & $0.13 \pm 0.05 \mathrm{a}$ & $0.10 \pm 0.01 \mathrm{a}$ & $0.19 \pm 0.06 \mathrm{a}$ \\
& $\mathrm{D}_{\text {MG }}$ & $1.86 \pm 0.49 \mathrm{~b}$ & $3.41 \pm 0.18 \mathrm{ab}$ & $4.14 \pm 0.16 \mathrm{a}$ & $4.25 \pm 0.08 \mathrm{a}$ & $3.71 \pm 0.08 \mathrm{ab}$ & $3.85 \pm 0.38 \mathrm{ab}$ \\
PLOT-2 & $\mathrm{H}^{\prime}$ & $2.26 \pm 0.46 \mathrm{~b}$ & $2.66 \pm 0.19 \mathrm{ab}$ & $2.76 \pm 0.01 \mathrm{a}$ & $2.69 \pm 0.16 \mathrm{ab}$ & $2.71 \pm 0.21 \mathrm{ab}$ & $2.48 \pm 0.17 \mathrm{ab}$ \\
& $\mathrm{E}$ & $0.74 \pm 0.09 \mathrm{a}$ & $0.79 \pm 0.04 \mathrm{a}$ & $0.78 \pm 0.01 \mathrm{a}$ & $0.75 \pm 0.05 \mathrm{a}$ & $0.73 \pm 0.02 \mathrm{a}$ & $0.72 \pm 0.07 \mathrm{a}$ \\
& $\mathrm{C}$ & $0.16 \pm 0.07 \mathrm{a}$ & $0.11 \pm 0.03 \mathrm{a}$ & $0.09 \pm 0.01 \mathrm{a}$ & $0.11 \pm 0.02 \mathrm{a}$ & $0.12 \pm 0.01 \mathrm{a}$ & $0.13 \pm 0.04 \mathrm{a}$ \\
& $\mathrm{M}_{\mathrm{G}}$ & $2.78 \pm 0.85 \mathrm{c}$ & $3.82 \pm 0.31 \mathrm{bc}$ & $4.55 \pm 0.11 \mathrm{abc}$ & $4.95 \pm 1.07 \mathrm{ab}$ & $5.72 \pm 1.40 \mathrm{a}$ & $4.29 \pm 0.55 \mathrm{ab}$ \\
& $\mathrm{H}^{\prime}$ & $1.84 \pm 0.06 \mathrm{~b}$ & $2.33 \pm 0.32 \mathrm{ab}$ & $2.66 \pm 0.50 \mathrm{a}$ & $2.59 \pm 0.01 \mathrm{ab}$ & $2.79 \pm 0.21 \mathrm{a}$ & $2.37 \pm 0.57 \mathrm{ab}$ \\
& $\mathrm{E}$ & $0.56 \pm 0.03 \mathrm{~b}$ & $0.79 \pm 0.07 \mathrm{a}$ & $0.81 \pm 0.11 \mathrm{a}$ & $0.74 \pm 0.02 \mathrm{a}$ & $0.78 \pm 0.05 \mathrm{a}$ & $0.69 \pm 0.14 \mathrm{a}$ \\
& $\mathrm{C}$ & $0.40 \pm 0.03 \mathrm{a}$ & $0.14 \pm 0.05 \mathrm{~b}$ & $0.11 \pm 0.07 \mathrm{~b}$ & $0.12 \pm 0.01 \mathrm{~b}$ & $0.09 \pm 0.03 \mathrm{~b}$ & $0.20 \pm 0.17 \mathrm{~b}$ \\
& $\mathrm{M}_{\mathrm{G}}$ & $1.86 \pm 0.36 \mathrm{c}$ & $2.73 \pm 0.44 \mathrm{bc}$ & $3.57 \pm 1.02 \mathrm{ab}$ & $4.52 \pm 0.42 \mathrm{a}$ & $4.94 \pm 0.33 \mathrm{a}$ & $4.18 \pm 0.59 \mathrm{a}$ \\
\hline
\end{tabular}

The number of green plants in the garden is increasing, which can effectively expand the greening range, and the green can also effectively relieve the pressure and vision. People can enjoy their mood in the process of viewing green plants. In the garden, not only must we plant green plants, but also plant ornamental flowers and plants, and match them with flowers, so as to effectively improve the viewing period of the garden landscape. The combination of tones and layered configuration is a particularly important way in the plant configuration process. The combination of different colors, leaf colors and heights can effectively enrich the level and color, create a multi-level, image and color landscape, and meet the modern people's viewing requirements for garden landscape.

\section{3 results and analysis}

\subsection{Realize the richness of landscape space landscape}

Landscape plants can effectively enrich the landscape through reasonable configuration, and other elements in the garden can create a medium, long-range and close-up view. Plant seasonal changes can dynamically change the shape of the color, the corridor, the posture, the mosaic and the branches, and the space can be changed at will. The configuration of different plants and the richness of seasonal changes can realize spatial reorganization, and can also effectively change the landscape of the garden, so that it has the effect of different landscapes, create a variety of garden viewing space, and effectively enrich the spatial level.

The constant changes throughout the year make plants have four seasons. Different plant species should be comprehensively considered and coordinated in the process of hierarchical configuration, superimposed and interspersed with each other, so that the garden space changes have a certain charm. Not only can it effectively realize the richness of the spatial level, but also realize the twists and turns of the garden space and the mutual movement of the vision. After that, the use of space size, virtual reality, retraction and opening and closing contrast can effectively improve the space art effect. If we achieve the combination of the four seasons and the time-shifting landscape, we can produce a stronger space-time appeal.

\subsection{Status of plant seasonal landscape}

Through actual investigations, it has been found that most of China's gardens are equipped with landscaping plants based on biodiversity needs, including grassland, woods and forest landscapes. According to statistics, the backbone trees in the park are mainly broad-leaved forests, and the seasonal phase is expressed by foliage, flowers and fruit plants. In general, landscape plant species are diverse and have distinct seasonal diversity. At present, the main plant viewing seasons in the gardens are in spring and summer. The four seasons in the garden are rich in landscapes, and the time of viewing different plants is quite different. Part of the viewing time is only 14-16d, some viewing time is several months, and some viewing time is one year.

\subsection{Garden space landscape plant season}

The seasonal landscape of plants in different regions should be created according to functional requirements and site conditions during the design process. For example, in the process of realizing the plant season landscape of urban parks, we must first comprehensively analyze the nature of the park, the relationship between the city and the characteristics of the site, and comprehensively meet the needs of various aspects to achieve scientific and rational allocation of plants, so as to effectively meet different needs. The requirements for the seasonal landscape design of different nodes in the park are also different. In the case of a comprehensive park, each landscape node in the park must achieve a reasonable mix of plants to create a beautiful park environment.

The entrance and exit of the park belong to the entire park facade, and it is also an important node to realize the interconnection between the park and the outside. In the design process, the surrounding conditions should be fully observed, especially in coordination with urban roads. Shrubs and trees can be set at the entrance to the gate to effectively protect the four seasons. In the process 
of realizing the combination of seasonal flowers, it is necessary to effectively display the seasonal changes. At the entrance and exit of the main entrance, a three-dimensional flower bed is set up to attract tourists with a reasonable mix of colored shrubs and flowers. In the quiet resting place of the park, you should create a comfortable and quiet botanical landscape, because this is a place for tourists to walk rest and enjoy the scenery, so the color of the plants can not be too lively. The plants set in the park square should be consistent with the overall style of the square, because the square belongs to the main distribution centre in the park and has certain artistic charm and publicity. You can use flowers and evergreen shrubs and trees to create a friendly and lively atmosphere.

\section{Discussion}

Seasonal changes in plants of cold gardens have a greater impact on plant shape. From spring to winter, the plants in the garden are constantly changing [6-7]. In the process, the shape of the plants also has obvious changes, and the seasonal changes can prove it. Different seasons have different effects on the garden landscape [8]. The seasonal changes of the garden plants have obvious periodicity, which also fully demonstrates the strong vitality of the plants. Successful landscape design must have an artistic appearance, while garden plants are the main landscape elements in the garden design process. Therefore, in the process of researching the creation of landscapes, it is necessary to pay attention to them, so as to effectively improve the allocation of garden plants and improve the quality of garden landscape construction. According to the climate of different regions, the adaptability of the land and the plant itself, it meets the needs of regional seasonal planting. In the process of selecting seasonal plants, using reasonable methods to achieve, focusing on the use of native tree species, not only can achieve the diversity of park plant species, but also effectively improve community stability.

\section{Acknowledgement}

Heilongjiang Provincial Department of Education Basic Research Project (2018-KYYWF-0936); The Core Talent of Jiamusi University (JMSURCGG2016-001); The China Scientific and technological innovation projects in Heilongjiang Province, college students: 201910222007.

\section{References}

1. Alshuwaikhat H M, Abubakar I. (2008) an integrated approach to achieving campus sustainability: assessment of the current campus environmental management practices. J. Sci. Journal of cleaner production, 16: 1777-1785.

2. Portney K E. (2013) Taking sustainable cities seriously: Economic development, the environment quality of life in American cities. MIT Press. The American.
3. Björkman M, Klingen I, Birch A N E, et al. (2011) Phytochemicals of Brassicaceae in plant protection and human health-Influences of climate, environment and agronomic practice. J. Sci. Phytochemistry, 72: 538-556.

4. Fjørtoft I. (2004) Landscape as playscape: The effects of natural environments on children's play and motor development. J. Sci. Children Youth and Environments, 14: 21-44.

5. McDonnell M J, Hahs A K. (2008) The use of gradient analysis studies in advancing our understanding of the ecology of urbanizing landscapes: current status and future directions. J. Sci. Landscape Ecology, 23: 1143-1155.

6. Bisgrove R, Hadley P. (2002) Gardening in the Global Greenhouse: the Impacts of Climate Change on Gardens in the UK. J. Sci. The UK climate impacts Programme, 17: 108-122.

7. Zhongxin L I. (2014) Application of plants in Chinese garden landscape. J. Sci. Canadian Social Science, 10: 143-155.

8. Thies C, Steffan-Dewenter I, Tscharntke T. (2003) Effects of landscape context on herbivory and parasitism at different spatial scales. J. Sci. Oikos, 101: 18-25. 